\title{
Simplified Stenting Methods during Laparoscopic Pyeloplasty in Children
}

\author{
Rustem Bishmanov ${ }^{1 \star}$, Mirzakarim Alchinbayev ${ }^{2}$
}

${ }^{1}$ Scientific Center of Paediatrics and Children Surgery, KAZAKHSTAN
${ }^{2}$ The Asfendiyarov Kazakh National Medical University, Urology Department, KAZAKHSTAN
${ }^{\star}$ Corresponding Author: bishman.ru@mail.ru

Citation: Bishmanov R, Alchinbayev M. Simplified Stenting Methods during Laparoscopic Pyeloplasty in Children. Electron J Gen Med. 2020;17(5):em236. https://doi.org/10.29333/ejgm/7935

\section{ARTICLE INFO}

Received: 27 Feb. 2020

Accepted: 4 Apr. 2020

\begin{abstract}
We are dedicated to evaluate a simplified methods for ureteric stent insertion during laparoscopic pyeloplasty in children.

After detect the cause of obstruction, UPJ resection was made. At that stage, we performed antegrade extracorporeal installation of stent by removing the proximal ureter through the lower skin defect after extraction of the trocar. That allowed for successful stenting under precise tactile and visual control. Then the ureter was reintroduced back into abdominal cavity. Dismembered LP by Hynnes-Andersen technique was made using $6 / 0$ absorbable monofilament suture. The second method of ureteric stenting: after the anastomosis of posterior pelvis wall is complete, puncturing with Veress needle between the optics and the upper trocar. The stylet was removed, after that we can introduce a stent through the needle hole with ensure accurate tactile sensations, maximum control over the stent direction.

Since January 2017, we have used this method in 32 children with congenital hydronephrosis were operated by LP. The proposed methods of ureteric stenting allowed reducing that stage to 3-10 minutes, with successful outcome in all cases. The children were discharged 5-7 days after surgery. No conversion to open surgery had to be performed.
\end{abstract}

Our experience shows that LP in children with congenital $\mathrm{HN}$ reduces the surgical burden on the patient, improves post-surgery quality of life. The proposed methods of antegrade intraoperative stenting significantly reduce the duration of surgery while improving the success rate of this key manipulation.

Keywords: hydronephrosis, pyeloplasty, laparoscopy

\section{INTRODUCTION}

Active advancement of pediatric endoscopic surgery in countries with developing medicine provides accumulation of considerable practical experience. The transition from open to endoscopic surgery has significantly improved the outcome of treatment and postoperative rehabilitation in children. Since 2012, some centers for pediatric surgery of the Republic of Kazakhstan have been successfully applying laparoscopic repair of hydronephrosis (HN). In the beginning, this method of $\mathrm{HN}$ correction was used in elder children. The experience gained and the use of modern endoscopic equipment allowed doing laparoscopic pyeloplasty (LP) in younger children. According to many studies, there was a consensus on the benefits of laparoscopy over traditional access: reduction of pain in early postoperative period, reduced length of hospital stays and quick recovery quality of life for children and parents. $(1,2)$.

According to the international and domestic experience, a frequent problem is the complicated installation of internal drainage of upper urinary tract using stents (3). This procedure occupies more than one third of the whole duration of surgery or failed (4). Main reasons include thin diameter of ureter and ureteropelvic junction (UPJ), thin and fragile ureter wall, the mobility and springing of the stent, the risk of stent twisting or damage, and the lack of precise tactile feedback during stenting. This is an acute problem as the method of drainage has a direct impact on the length of hospital stay, successful formation of anastomosis, and the period of postoperative rehabilitation of the patient. The existing methods of preoperative retrograde ureteric stenting are associated with a high risk of ureter perforation, the risk of the stent transection during pelvis resection or ureter spatulation. The pre-set stent complicates the ureter spatulation and creation the posterior wall of anastomosis (5). This report describes the methods of simplified ureteric stenting during LP in children.

\section{MATERIALS AND METHODS}

\section{Patients}

We obtained approval from our institutional internal review board (The Asfendiyarov Kazakh National Medical University, Institutional Ethics Committee No. 414/17), all 


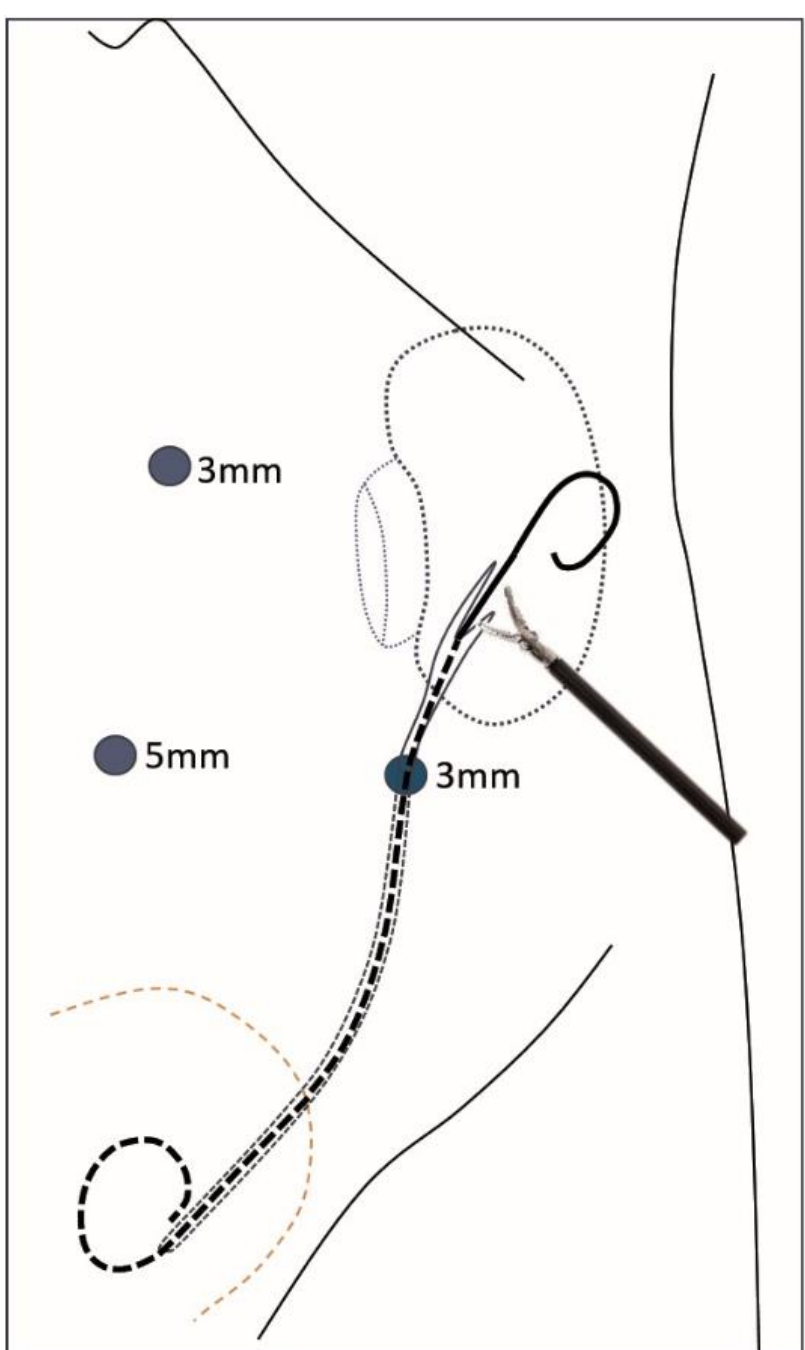

Figure 1. Antegrade extracorporeal installation of ureteric stent

parents provided written informed consent and all patients provided written assent when appropriate. All children underwent diagnostic testing including ultrasound examination of the urinary system, voiding cystography, and excretory urography. All patients were diagnosed with unilateral congenital HN. The indications for LP included HN of third degree with a healthy contralateral kidney, without significant renal compromise (GFR higher than G3 or CKD lower than $60 \mathrm{ml} / \mathrm{min} / 1.73 \mathrm{~m}^{2}$ ), fusion abnormality or kidney position anomalies.

\section{Operative Technique}

Patient position was lateral decubitus on the healthy side, angled by 45 degrees. The first $5 \mathrm{~mm}$ trocar was regularly placed above the umbilical ring to introduce 30-degree optics. The following general examination of abdominal cavity was done to detect any additional pathology. Two 5 (3) $\mathrm{mm}$ manipulation trocars were installed from the side of the affected kidney at the edge of the rectus abdominis muscle to form a rhombus with the umbilicus as the lower vertex, and the projection of the affected kidney as the upper vertex. The fourth additional trocar was installed to elevate the liver. Abdominal pressure was maintained at $8-10-14 \mathrm{~mm} / \mathrm{Hg}$, it depends to age. The kidney was assessed by mobilization of hepatic or splenic flexures of large bowel. After the necessary kidney exposure, the pelvis and ureter were mobilized to

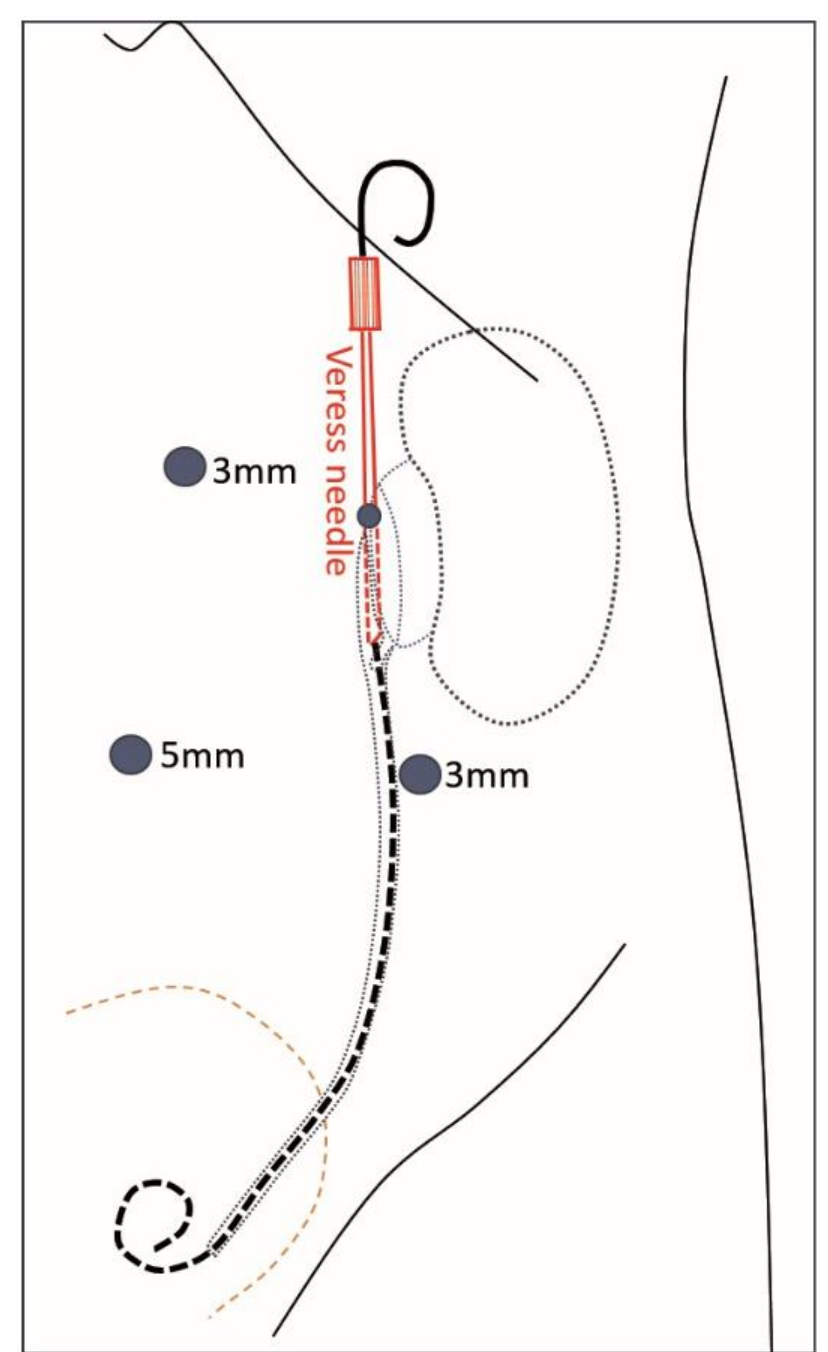

Figure 2. Introducing a stent through the Veress needle

detect the cause of obstruction. Next, the upper vertex of renal pelvis was fixed by monofilament suture to the abdominal wall. UPJ resection was made. At that stage, we performed antegrade extracorporeal installation of stent by removing the proximal ureter through the lower skin defect after extraction of the trocar by gently pulling the ureter with Kelly forceps. That allowed for successful stenting under precise tactile and visual control (Figure 1). Then the ureter was reintroduced back into abdominal cavity followed by anastomosis with renal pelvis. Dismembered LP by Hynnes-Andersen technique was made using interrupted stitches using $6 / 0$ absorbable monofilament suture.

The second method of ureteric stenting: after the anastomosis of posterior pelvis wall is complete, puncturing with Veress needle between the optics and the upper trocar. The stylet was removed, after that we can introduce a stent through the needle hole with ensure accurate tactile sensations, maximum control over the stent direction and reduce the risk of gas leak (Figure 2). The stent size $3 \mathrm{Ch}-4 \mathrm{Ch}$. After that, the anterior wall was sutured, and the peritoneum defect was tightly sutured with leaving one draining lumbostoma. 


\section{RESULTS}

Since January 2017, we have used this method in 32 children ( 11 boys and 21 girls) aged 3 months to 3 years with congenital $\mathrm{HN}$ of third degree were operated by LP. All patients were diagnosed with unilateral congenital HN (25 left sided). The duration of surgery in average 100 minutes. With experience accumulation, the duration of surgical intervention was decreasing to reach the duration of open pyeloplasty, about 60 minutes. The proposed methods of ureteric stenting allowed reducing that stage to 3-10 minutes, with successful outcome in all cases. The children were discharged 5-7 days after surgery. Antibacterial, intravenous fluid and symptomatic therapy were significantly reduced. There were no wound postoperative infections. No conversion to open surgery had to be performed. Blood loss was minimized due to less traumatic access. In all cases, the stents were removed after 1.5 months by cystoscopy. X-ray urological control after 4 months showed positive postoperative dynamics.

\section{DISCUSSION}

Early diagnosis of congenital kidney pathologies, as well as excellent results on the correction of UPJ obstruction in children of the younger group, led to the fact that the main contingent of patients is children under 3 years of age (9). LP by Hynnes-Andersen technique in children of this group is a common procedure at the present time and has determined many positive aspects in comparison with traditional access to the kidney $(1,2,10)$. But in same time, some stages of this manipulation were technically complicated when using video endoscopic surgery, as for the plastic surgery of the ureteropelvic segment - this is the assembly (modeling) of a 3dimensional anatomical structure through a 2-dimensional monitor. The process of intracorporeal installation of JJ stent has also become more complicated, since we reduced our tactile sensitivity when undergoing anatomical narrowing and bending of the ureter, especially at the level of the UVJ, this increases a certain risk of intraoperative complications trauma to the fragile and thin walls of the ureter, penetration, deformation dysfunction and migration of an improperly installed JJ stent, the risk of separation of the created anastomosis due to the excess of the difficult to control stent installation effort $(6,7)$. The intraoperative retrograde cystoscopic installation is difficult in that it is necessary to change the position of the child's body, for this manipulation, it is also often rather difficult to detect ureteral orifice. We understand that there are other methods of kidney drainage in the postoperative period, and drainage methods are also described, in our opinion, they were developed for the reason that surgeons often faced a situation where they could not install a JJ stent or, it took a lot of time (8). We also consider the use of external pyelostomas or drainless methods in children of the younger group possible, but for very limited indications, since they pose an unreasonable risk of infection, impaired UPJ or stoma, risk of UPJ injury, urinary leakage, and a decrease in the quality of life in the postoperative period. The stenting technique we used was described in adults and in children, where excellent results were obtained in an efficient and quick installation $(11,12)$. The thin abdominal wall simplified extracorporeal excretion of the ureter, spatulation, first suture and stent placement. We also proposed and implemented the installation of a JJ-stent using a Veress needle, so we achieved a reduction in the leakage of warm and moist gas from the abdominal cavity, easier navigation of directions, tactile sensitivity of the passage of anatomical bends and narrowing of the ureter, dosed force.

\section{CONCLUSION}

Our experience shows that LP in children with congenital $\mathrm{HN}$ reduces the surgical burden on the patient, improves postsurgery quality of life. The proposed methods of antegrade intraoperative stenting significantly reduce the duration of surgery while improving the success rate of this key manipulation.

\section{REFERENCES}

1. Bonnard A, Fouquet V, Carricaburu E, Aigrain Y, Elghoneimi A. Retroperitoneal laparoscopic versus open pyeloplasty in children. The Journal of Urology. 2005;173(5):1710-3. https://doi.org/10.1097/01.ju.0000154169.74458.32 PMid:15821565

2. Ravish I, Nerli R, Reddy M, Amarkhed S. Laparoscopic Pyeloplasty Compared with Open Pyeloplasty in Children. Journal of Endourology. 2007;21(8):897-902. https://doi.org/10.1089/end.2006.0411 PMid:17867949

3. Tan H. Laparoscopic anderson-hynes dismembered pyeloplasty in children. The Journal of Urology. 1999;162(3):1045-7. https://doi.org/10.1016/s0022-5347 (01)68060-1

4. Rudin YuE, Maruchnenko DV, Arustamov LD, Lagutin GV. Endosurgery for the treatment of pyeloureteral obstruction in children. Eksperimental'naya i klinicheskaya urologiya. 2014;4:110-5. (In Russ.)

5. Kumar UGill I. Tips and Tricks In Laparoscopic Urology. 1st ed. London: Springer Verlag; 2007:204-7. https://doi.org/10.1007/978-1-84628-160-0

6. Arumainayagam N, Minervini A, Davenport $\mathrm{K}$, et al. Antegrade versus retrograde stenting in laparoscopic pyeloplasty. J Endourol 2008;22(4):671-4. https://doi.org/ 10.1089/end.2007.0210 PMid:18419213

7. Minervini A, Siena G, Masieri L, Lapini A, Serni S, Carini M. Antegrade stenting in laparoscopic pyeloplasty: feasibility of the technique and time required for stent insertion. Surg Endosc 2009;23(8):1831-4. https://doi.org/10.1007/s00464008-0272-7 PMid:19118431

8. Garg RK, Menon P, Rao KL, Arora S, Batra YK. Pyeloplasty for hydronephrosis: Issues of double $J$ stent versus nephrostomy tube as drainage technique. J Indian Assoc Pediatr Surg 2015;20:32-6. https://doi.org/10.4103/09719261.145444 PMid:25552829 PMCid:PMC4268754

9. Metzelder M, Schier F, Petersen C, Truss M, Ure B. Laparoscopic Transabdominal Pyeloplasty in Children is Feasible Irrespective of Age. Journal of Urology, 2006;175(2):688-91. https://doi.org/10.1016/s0022-5347 (05)00179-5

10. Piaggio LA, Franc-Guimond J, Noh PH, Wehry M, Figueroa TE, Barthold J, González R. Transperitoneal Laparoscopic Pyeloplasty for Primary Repair of Ureteropelvic Junction Obstruction in Infants and Children: Comparison with Open Surgery. Journal of Urology, 2007;178(4S):1579-83. https://doi.org/10.1016/j.juro.2007.03.159 PMid:17707047 
11. Nadu A, Mor Y, Ramon J. Direct extracorporeal ureteric stenting during laparoscopic pyeloplasty: a novel technique. BJU International, 2009;103(6):844-7. https://doi.org/10.1111/j.1464-410x.2009.08462.x PMid:19260855
12. Kocherov S, Lev G, Chertin L, Chertin B. Extracorporeal Ureteric Stenting for Pediatric Laparoscopic Pyeloplasty. European Journal of Pediatric Surgery, 2015;26(02):203-6. https://doi.org/10.1055/s-0035-1546756 PMid:25774958 